\title{
COLLABORATIVE ENGINEERING COMMUNITIES IN SHIPBUILDING
}

\author{
Norbert Gronau \\ Business Information Systems, University of Potsdam, GERMANY; ngronau@ rz.uni-potsdam.de \\ Eva-Maria Kern \\ Production Management; Technical University of Hamburg, GERMANY; e.kern@ tuhh.de
}

\begin{abstract}
Collaborative Engineering is a promising concept to increase the competitiveness of companies. Target of this paper is to describe the industrial application of this approach, considering shipbuilding as an example. Besides the engineering partners' needs to collaborate during the product development phase, there are many other stakeholders who are interested in the product ship along its whole life cycle. Therefore the Concept of Collaborative Engineering is extended by introducing the idea of Communities. Requirements on Communities in Engineering are deduced. Based on this an architectural framework for Collaborative Engineering Communities is described. Concluding research topics which have to be discussed for practical realization are outlined.
\end{abstract}

\section{INTRODUCTION}

Collaborative Engineering (C-Engineering) defines the internet supported design of distributed product development processes. Technological as well as organizational and human aspects have to be considered (Kersten / Kern, 2002). The engineering partners either belong to different departments or locations of one company or are part of a virtual network consisting of different companies including suppliers and customers. The cooperation of companies in product development is already executed in many industries like the shipbuilding or automotive industry. To use the know-how of the suppliers efficiently, they have to be integrated in the development process as early as possible. Internet-technologies open new possibilities for the design of interaction mechanisms and can therefore support a tight integration.

Particularly for the engineering of complex products the specific contributions of numerous partners have to be coordinated. The difficulty of generating an efficient over-all process lies in the heterogeneity of the partner specific organizational structures and processes as well as the used IT infrastructures. The following section illustrates this challenges using shipbuilding as an example. 


\section{COLLABORATIVE ENGINEERING IN SHIPBUILDING}

Shipbuilding is an impressive example for complex distributed engineering processes. More than $75 \%$ of the creation of value is performed by numerous suppliers. Besides material, component and system suppliers also engineering companies can be used to support the shipyard with construction performance in various extents.

\subsection{Characteristics of Distributed Product Development in Shipbuilding}

Product development in shipbuilding can be characterized as follows (Kern / Hahn / Benger, 2003; Kersten / Kern, 2003):

Product: Due to the high complexity of the ship, big volumes of data and information have to be exchanged between the engineering partners. The interdependency between the specific tasks of the main suppliers and the shipyard is very high. This means that a change in one system can possibly affect several other systems or even the whole design of the ship. To guarantee that each engineering partner works with the actual documents, an efficient data, information and change management is required.

Process: In Germany the shipyards concentrate on developing and producing small series or even uniques. So the standardization potential of the engineering processes is low. There is no sharp separation between development process and production. Therefore running insights coming up during the progress of the engineering process as well as changing customer wishes cause high demands on information and change management.

Partner constellation: The collaboration is characterized by a large number of various companies, which differ very strongly in size, structure, tasks and importance for the engineering process. Therefore the partners have different views of the process, need a different formatting and editing of data and have different rights of data and information access. Also the companies' terminologies vary in certain extents which can cause problems in finding a common understanding. Further changing partner constellations for each shipbuilding project and very strong influence of the customers have to be taken into account.

Information and Communication technology: The high number of companies joining the project causes numerous different IT-Infrastructures and company specific premises. This often complicates the data exchange between the partners.

\subsection{Challenges of Implementing Collaborative Engineering in Shipbuilding}

Based on the characteristics described above, multiple challenges have to be taken into account by implementing Collaborative Engineering in Shipbuilding. As mentioned before, organizational, technical and human aspects have to be considered.

- Organization: To generate a common over-all process the specific collaboration and information needs of the partners have to be analyzed. Based on this, the necessary intensity of interaction has to be chosen. Depending on the partners' position and importance in the engineering process their tasks, rights and duties have to be defined. 
- IT-Infrastructure: The selected system has to support all necessary interaction processes between the partners. Different intensities of interaction like communication, coordination and collaboration have to be enabled (Gronau, 2002). The IT support must be designed in a way which enables partners independently form their infrastructure to join and use it with a minimum of effort. The different roles of the partners concerning their rights and views must also be supported by appropriate mechanisms.

- Human aspects: People have to get involved in designing their new collaborative working environment. Only if it is designed to their needs and if they learn how to use the new technology, they will accept the new way of working.

\subsection{From Collaborative Engineering to Life Cycle Management}

As described above, the concept of Collaborative Engineering primarily focuses on the product development and, like in shipbuilding, on the production process. But in viewing product life cycle it becomes evident that the engineering partners often are also involved in succeeding phases of a ships life. In addition to them a couple of other stakeholders exist, who are interested in this product. Figure 1 generally shows possible stakeholders of a products life cycle. They are determined by the type of product and the structure of the dedicated industry.

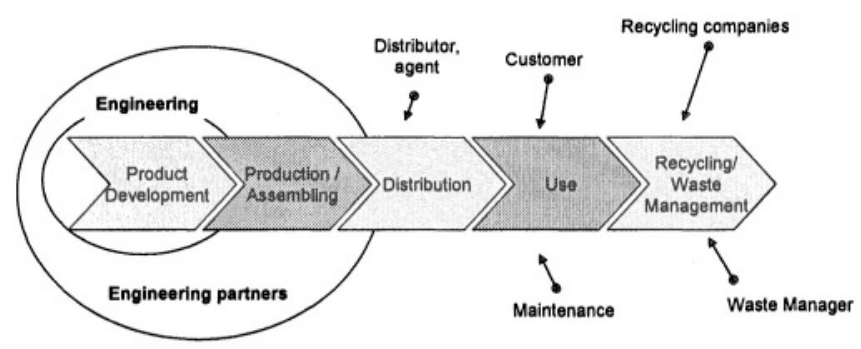

Figure 1 - Stakeholders of the life cycle of a product

In shipbuilding these stakeholders can for example be: the ship-owner, the charterer, the classification society, which controls the operating condition of the ship, shipyards, suppliers and other companies, who rebuild or maintain ships, ship agents, assurance and financing companies, shipbreaking companies, the ship's crew, software companies for $\mathrm{CAD}$, engineering service providers, etc.. These companies differ very strongly in their targets, sights and ambitions but are joined by their common interest concerning the product ship. All of them need product related data and information depending on their specific needs and requirements. Usually, every group has an own information management and information system and collects data by itself. Possible synergies between the information systems are very rarely used. Therefore the same data are collected repeatedly, information is not completely available along a product's life cycle and relevant insights of succeeding phases are often lost for preliminary ones.

To solve the above described problems, the idea of Life Cycle Management could be a starting point to transform traditional engineering networks into Engineering Communities. Life Cycle Management is the collecting, processing and 
storing of all relevant product related data along the whole life cycle of a product. Engineering partners as well as all stakeholders can voluntarily join the community. Target of the approach is to integrate the so far separately working information systems of the community members to obtain a linking between the single phases of product life cycle.

\section{COMMUNITY ASPECTS IN PRODUCT DEVELOPMENT}

The partners in the shipbuilding industry shall or want to cooperate during the whole product life cycle. Therefore it is useful to extend the concept of Collaborative Engineering by integrating the approach of communities.

In the following section the term community is defined, its transfer into the realm of Engineering with the introduction of so called Collaborative Engineering Communities is described and requirements for these communities are formulated.

\subsection{Collaborative Engineering Communities}

Communities are one kind of loosely organized groups discussed in the field of internet economy. Lechner and Schmid (1999) define communities as an association of singles (agents) which share a common language, values and interests and communicate with each other in roles using electronic media. These groups define themselves nearly completely by a common interest in a special topic. Their connection is voluntarily and not invoked or determined by hierarchies. Earlier communities are used only to communicate or to exchange information. Therefore only a few rules exist how to behave in a community.

A Collaborative Engineering Community (CEC) will be understood as an organizational kind of collaboration between firms in the area of product development, which integrates all users and organizational units joining in the product life cycle and which provides all data, information and knowledge elements necessary for telecooperation. Figure 2 shows a differentiation between communities and other virtual groups.

A real collaboration with the prerequisites openness and ability to transparency is only possible with selected (authenticated) partners.

Especially in the realm of engineering a growing trust relationship is a necessary condition for intensive interactions. Common approaches for the generation of Engineering Networks (Puffaldt, 2001) are widened by the consideration of late phases in product lifecycle and by the integration of customers (Richter / Krause, 2001) or other claim groups. For the usage in the area of shipbuilding the CEC approach delivers the following application possibilities: Inside the community very fast tender invitations can be placed and negotiated to choose engineering partners for new ship projects or for refurbishment or maintenance. Information and experience gained during the ship's usage are collected up to now decentrally e.g. by the owner, by repair or overhaul companies or by the classification society. 


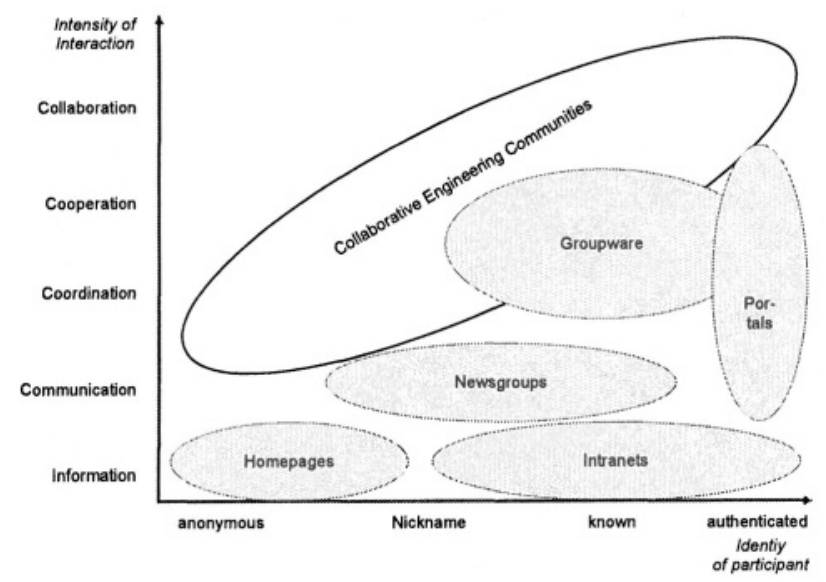

Figure 2 - Categorization of Collaborative Engineering Communities under interaction and identity (Gronau, 2002)

With a CEC it is possible to collect and categorize relevant data and information and to deliver these demand fulfilling. For instance shipyards and suppliers can use this information to derive insights concerning technical improvements or new requirements from the owner. Additionally it would be possible to give an overview over important events during the whole usage period of the ship for ship agents or charterers.

\subsection{Requirements for Collaborative Engineering Communities in the Ship- building Industry}

The potential users of communities in the area of ship engineering create and use huge amounts of data in different formats and documents. They work together in knowledge-intensive processes with communication on a large scale. Therefore the CEC has to provide software tools, which support asynchronous as well as synchronous cooperation. Asynchronous cooperation (e.g mailing and task lists, discussion groups, archive functions, administration of contents like links or text) covers the demand for a loose-coupled cooperation in communities. Important for the acceptance is the possibility to work with these functions without the necessity to install proprietary client software. All asynchronous functions must be available via web browser and Internet access using the http-protocol. Synchronous cooperation ( e.g. joint viewing, joint editing, joint meeting). The conference support tools have to be integrated into the community portal as well.

The line-up of these communities can vary during the product life cycle. Therefore a generation of benefits is only guaranteed, if CECs fulfil the following requirements:

- They need a lot of organizational and technical flexibility to reach fast and efficient changes in the configuration of partners and in the process models of product development with a low effort of hierarchical interventions, if possible.

- They shall reach a fast common semantic and content-related understanding of the users.

- $\quad$ They have to make available data and information for the users depending on 
their roles and needs in an appropriate form of presentation (degree of details, scope, visualization) and they have to maintain different levels of trust.

- Their information systems architecture, which is defined as a planned cooperation of technical, organizational, cost-related and social aspects during development and usage of business information systems, needs a high ability of self-organizing and partial decision autonomy to be able to integrate new cooperative partners into the engineering community very fast.

\section{ARCHITECTURAL FRAMEWORK}

Product structure and the information that can be derived from it, play an important role during the design of a ship and during the usage as well. To connect all participating persons during the whole life cycle of the ship this data structure (or schema) delivers the scaffolding for the exchange of information. Only if it is possible to assign usage experiences to certain assembly groups or parts, this information can be gathered and used later for the optimization of the construction for a new ship. The main challenge is here to prepare the product data structure for the different views of the participants. For instance the design department has an other view onto the product data than the work planning or the purchasing departments. These different views are managed today with engineering data management systems (like Windchill from Parametric Technologies Corp.)

When the horizon is now widened to encompass the stages of usage and waste disposal, also all in these stages relevant views have to be captured and modelled. Only if it is successful to capture the work behaviour, the think patterns and the terminology of the participants and to deliver a valid neutral product structure it is possible to integrate a community portal as an information turntable for the product life cycle management.

In the next step the integration of such a portal into the workplace of the user is necessary. Integration tasks include the support of diverse data formats. In every stage of the life cycle different tools and documents exist for modelling, analysis or processing of product related data. All these documents shall be administrated in the community-portal without inefficient conversion and shall be usable for cooperation. Nowadays, this requirement is not fulfilled for the area of engineering due to heterogeneous system worlds and missing standards. Based on the considerations in the past sections an architectural model for collaborative engineering communities (Gronau, 2002) was developed (Figure 3).

Different groups of users or participants at the engineering process are integrated into the Collaborative Engineering Community. It was detected as useful to grant access for all types of users by a common portal. A portal not only indicates the unified access but at the collaborative engineering community it also delivers the personalization after an appropriate authentication. The results of personalization and authentication determine the possibilities for the members to move inside of the collaborative engineering community. The results are represented by the view models in the user model. Here it is defined, which information is accessible by a certain group member in a certain role. The accessibility is defined for objects, process steps and competitive relevance. A user in the role of a system supplier sees 
these parts in the object area, which are delivered by himself and surrounding parts to be able to check assemblies.

In the process area the accessibility of certain process information is defined. The role "external service" perhaps does not need information from the usage stage of product life cycle. On the other hand user groups as cooperation partners should only be able to see product properties from the stage of product definition and then be integrated highly into the results of field surveys.

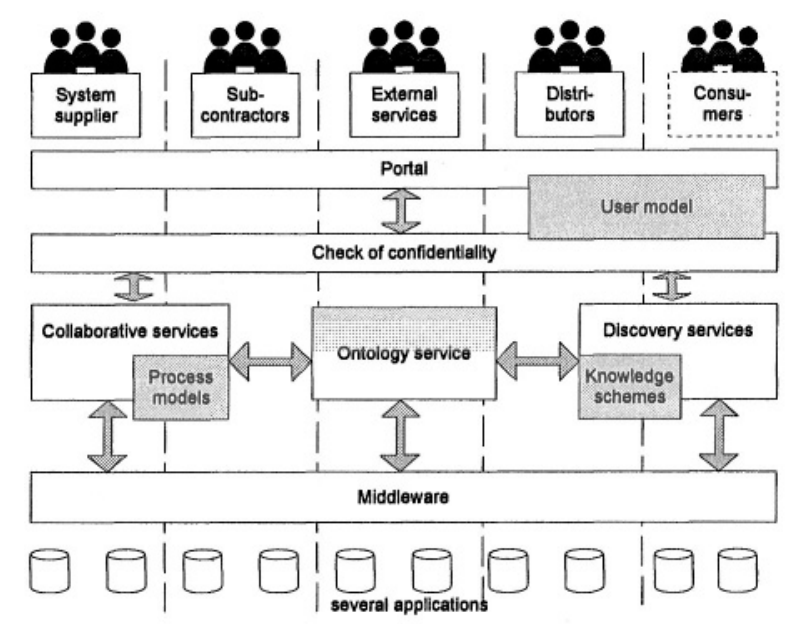

Figure 3 - Architectural proposal for a collaborative engineering community

Crosswise to these aspect definitions basing on objects or process stages the degree of confidentiality is defined for sets of information. The resulting view of users on the collaborative engineering community is determined by the totality of restrictions and releases.

A block layer between portal and system functionality supervises during all activities of the users, that the maximum valid view is not exceeded. The block layer is formed as a separate software module to log accesses and access trials and to canal accesses. This makes the protection against security holes easier.

On the next layer of the architectural model of the CEC community services are provided. It is stated that the most users need the discovery services, which allow a supply with information or reports about process steps or objects. The discovery services can be realized by search engines, information warehouse technologies, life time tracing systems (Anderl et. al., 2000) and other on digital past data basing information procurement tasks.

As a supporting element the discovery services use a meta model of the information sources available in the community, which is named as a collection of knowledge schemas. This kind of meta modelling can be compared with the representation of repositories in data warehouses (Mertens / Wieczorrek, 2000) and contains descriptions of knowledge sources, time data (dates of creation and of input into the system), source descriptions, classifications, key words, format information and links between the knowledge sources.

The collaborative services provide tools for the joint distributed design and engineering. Today available systems allow joint viewing, digital mock-up and joint 
editing. These functions will be enlarged with rising bandwidth on the internet. Process models are used here in the same function as the knowledge schemes of the discovery services.

A central element to assure a common understanding between different groups of users is the usage of a common world of terminology. Independent term contexts are defined in the different user groups at first, because special and local networks of terms and meanings are used. In the process of communication with other user groups terms are interpreted in a different manner, which impairs the efficiency of communication and any collaboration based on that communication. A solution for this problem is the usage of ontologies (Maedche, 2001). This task is fulfilled by a component called ontology service. A proposed task of the ontology service is the standardization of different term usage and the generation of hints if not solvable conflicts occur. Then a manual solution of the problem is necessary to extend the taxonomic knowledge.

The access to the applications reachable via the collaborative engineering community is delivered by a middleware building block. The middleware provides appropriate functions or applications for every user according to the user model with the permitted set of data and information. Possible applications are business administration and information systems (Gronau, 1999), production engineering tools, product data management systems and CAD systems. CAD systems are a possible class of applications because they support collaborative work at least in a certain extent (Ibelings, 2001).

\section{IMPLEMENTATION: A COMPONENT-ORIENTED FRAMEWORK FOR CEC}

Knowledge Management (KM) systems like CEC have no special qualities that would justify to exclude them from the major trend of building information systems using a component-oriented approach (Szyperski, 2002) to reduce the cost of development as well as enhance flexibility and hence achieve sustainable architectures resp. long running systems. In fact these issues affect especially KM systems for they are not "primary" systems in two ways. KM systems have to integrate, mediate and enrich "basic" information that comes from technically different components, namely from the "standard" information systems of an organization. The later include the "first priority" systems of a company, while KM systems are usually rated rather as "useful" but "necessary" - therefore a KM system's financial requirements should be "moderate" at the latest after deployment.

The CEC approach discussed in the last section shows that there is a need for a "domain specification" for knowledge management software support: Developing a component for a KM system still rises too many questions regarding entities that should be easily recognized as common business objects or vertical facilities with clearly understood positions in a typical components framework for KM systems. Such a framework is currently developed (Gronau / Laskowski, 2003; Figure 4). The elaboration of the framework covers two main aspects:

Interfaces for a KM systems information sources, services and applications: What are the basic and extended mechanisms that these types of components offer or need and that should and can reasonably be unified? 
Core components of a KM system: Some features are necessary to run a KM system that integrates a variety of components and changes over time (e.g. user profiles). Others are candidates for "common knowledge facilities" because of their high potential to increase the overall quality delivered by many components (e.g. meta data and internal association services). Of course a complete KM framework includes such functionality. But it is conceptually crucial that the core system provides unified and logically centralized access points to these facilities, while the implementation might reside in external components as well.

To fully exploit the advantages of the component-oriented approach KM systems have to operate distributedly. A KM system should be able to integrate components externally provided by using the emerging web-services technology (Vasudevan, 2001) and it should be able to cooperate with other KM systems. The option to integrate a variety of external knowledge-oriented services like ontologies, analysis tools or community support with reasonable effort facilitates the vision of an evolving KM system: Not only the accessible information sources but the complete functionality of the KM system can adopt to changes in the information architecture of an organization. This is of specific interest in knowledge management, because KM systems implement knowledge management strategies and thus are expected to influence the way individuals, organizational units and an organization as a whole handle information. In most standard information systems flexibility is mainly needed to adopt to externally caused "drift effects" in user or technical requirements but change is not inherent to their purpose.

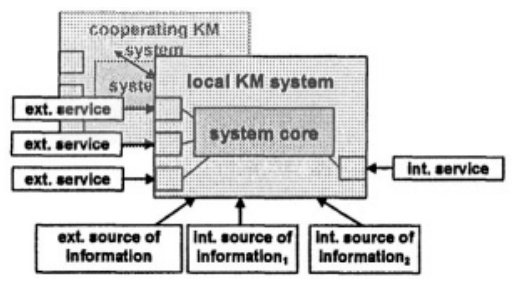

Figure 4 -Architecture for KM systems usable in CEC (Gronau / Laskowski, 2003)

With extended (and affordably priced) flexibility a local setup and maintenance of $\mathrm{KM}$ systems becomes a more common scenario, e.g. local KM systems in departments that have very special and important knowledge intensive tasks in a company. To prevent counterproductive "knowledge islands" to emerge, in the design of the core KM system resp. the "common knowledge facilities" there has to be a major focus not only on integration but on cooperation as well.

\section{CONCLUSION AND FURTHER PROSPECTS}

For the shipbuilding industry the concept of Collaborative Engineering as well as the formation of collaborative engineering communities are suitable approaches to improve collaboration between all participants involved into the product development process and the whole product lifecycle. Various research projects show that the ship building industry is willing to implement C-Engineering for selected projects and partnerships. This is possible because the ship yards and their 
suppliers can clearly see the improvement potentials for each partner. Besides the creation of an appropriate technological support the future challenges lie on one hand in working out adequate implementation strategies, on the other hand in developing concepts and procedures which allow a flexible integration of changing partners. For a successful practical formation of Collaborative Engineering Communities a number of research topics have to be discussed which could not be dealt within this paper. Some of them are listed below:

- How could the benefits of working together in a CEC be quantified?

- Which benefits can be expected for the different types of partners?

- Which efforts should be taken to establish a CEC?

- How could companies be motivated to join a CEC and publish their knowledge?

- How is it possible to create trust between the members of the CEC?

- Does the concept of CEC cause the need of changing legal conditions?

- Who is responsible for the reliability of the information published?

- Ships usually have a long lifecycle. How is it possible to store relevant data and information independently from the systems architecture of the CEC?

\section{REFERENCES}

1. Anderl R, Daum B., John H. From product data management to the management of product life cycle (in German) ProduktDatenManagement 1 (2000) 2, 10-15, 2000

2. Gronau, N. Collaborative Engineering Communities - Architecture and Approaches for Integration In: Loos, P. u.a.: E-Business - Integration industrial ERP-architectures (in German). Göttingen 2002

3. Gronau N. Management of manufacturing and logistics with SAP R/3. 3rd edition München;; Wien 1999

4. Gronau, N., Laskowski, F.: K_SERVICES: From State-of-the-Art Components to Next Generation Distributed KM Systems. In: Khosrow-Pour, M. (Hrsg.): Information Technology and Organizations: Trends, Issues, Challenges and Solutions. Proc. of the 2003 Information Resources Management Association International Conference, Philadelphia, PA, USA, May 18-21, 2003, S. 1100-1102

5. Ibelings I. Collaborative CAD Systems (in German). Industrie Management 17 (2001) 3, 53-61, 2001

6. Kern EM, Hahn A, Benger A. Peer-to-Peer Process Integration in Virtual Engineering Organizations. In Proceedings of the 11th IFIP International Conference on Virtual Enterprises PRO-VE 2003, Lugano. Processes and Foundations of Virtual Organizations, 433-440, Kluwer, Boston 2003

7. Kersten W, Kern EM. Distributed Product Development as a Core Element of Supply Chain Management, In Proceedings of the 2003 IEEE Conference on Emerging Technologies and Factory Automation; Volume 2; 35-39; Lisbon 2003

8. Kersten W, Kern, EM. Internet supported cooperation in product development (in German), In VDIZ 144 , Nr. 7/8, 47-49, 2002

9. Lechner U, Schmid, B et al. A reference model for communities and media (in German) - Case Study Amazon.com. In: Englien, M.; Homann, J. (Eds.): Communities in New Media (GeNeMe99), Lohmar 1999, 125-150

10. Maedche, A, Staab S. Studer, R. Ontologies (in German). Wirtschaftsinformatik 43 (2001) 4, 393 395

11. Mertens, P, Wieczorrek, HW. Data X Strategies. Data Warehouse, Data Mining and operational systems in practice (in German). Berlin Heidelberg New York 2000

12. Puffaldt J. Cooperative product development (in German). Industrie Management 17 (2001) 3, 25-28

13. Richter, K, Krause, L. Usage of product data management as key technology for E-business (in German). Industrie Management 17 (2001) 3, 81-85

14. Szyperski, C.; Gruntz, D.; Murer, S.: Component Software - Beyond Object-Oriented Programming, Second Edition, Addison-Wesley/ACM Press, 2002

15. Vasudevan, V.: A Web Services Primer: A review of the emerging XML-based web services platform, examining the core components of SOAP, WSDL and UDDI. O'Reilly XML.COM, 2001 http://www.xml.com/pub/a/2001/04/04/webservices/ 